\title{
Diálogos del exilio republicano español. Desembarcar en Futuro $(1939)^{1}$
}

\author{
Lucía Di Salvo León ${ }^{2}$
}

Resumen: Futuro, México (1933-1946), publicación cultural de izquierdas surgida como una alternativa renovadora de reflexión sobre la realidad mexicana y latinoamericana y que estableció un debate polifónico frente a los peligros que asediaban $\mathrm{Eu}-$ ropa. Notamos, particularmente, enunciados ligados al exilio que obligaban a una acción responsiva. Estos enunciados multiacentuales, no trabajados hasta el momento, conforman nuestro corpus. En este marco, primeramente, analizaremos desde la perspectiva dialógica bajtiniana, de qué modo se constituyen las redes entre los participantes de la revista. En segundo lugar, observaremos cómo se establecen espacios de polifonía en un artículo extraído de la revista. Esta puesta en escena de múltiples voces (asociadas a posiciones políticas diversas) confiere un sentido más amplio de cómo se dio el proceso de acogida de los exiliados en México. Para finalizar, a partir del análisis de «Poemas de la guerra» extraídos de la revista, notaremos de qué modos se constituyó un frente poético solidario que enarboló la palabra como medio de lucha y solidaridad.

Palabras clave: Diálogos - Exilio republicano español - Revista Futuro - Solidaridad - Poesía
Abstract: The left-wing cultural publication Futuro (México,1933-1946) appears as a rejuvenating alternative reflection upon the mexican and latinoamerican reality, and sets up a polyphonic debate in view of the dangers threatening Europe. In particular, we focus on statements related to the exile which call for a responsive action. Those multaccent, not yet studied, statements define our corpus. In this context, we shall first analize from Batjin's dialogical perspective how networks between contributors to the magazine are established. We will then study how polyphony spaces are set up in an article from the magazine. This staging of multiple voices (linked to diverse political stances) provides a wider sense of how the reception process of exiles occurred in México. Finally, we will make an analysis of «war poems» («Poemas de la guerra») from the magazine. By doing so, we will point out the the ways in which a solidary poetic front is established, in which words are brandished as means for finghting and solidarity.

Keywords: Dialogues - Spanish republican exile - Futuro magazine - Solidarity Poetics

\footnotetext{
${ }^{1}$ Trabajo recibido el 15/10/2017. Aceptado el 07/12/2017.

${ }^{2}$ Licenciada y Profesora en Letras por la Universidad de Buenos Aires. Becaria doctoral en el programa de Doctorado Interdisciplinario en Humanidades, Artes y Ciencias Sociales (Universidad de Valparaíso) y tesista Fondecyt (Comisión Nacional de Investigación Científica y Tecnológica). Contacto: lucia.disalvo@postgrado.uv.cl
} 


\section{Introducción ${ }^{3}$}

«No son huéspedes de México, sino de Vicente Lombardo Toledano» ${ }^{4}$

Futuro (México, 1933-1946), revista fundada y dirigida por Vicente Lombardo Toledano, ${ }^{5}$ fue una alternativa renovadora en el contexto del proyecto revolucionario mexicano con la llegada a Palacio Nacional del general Lázaro Cárdenas. Se trataba de un espacio de debate sobre las contingencias del suelo Latinoamericano y los peligros que asediaban Europa, particularmente la amenaza del fascismo. Con más de 40.000 ejemplares circulando mensualmente ${ }^{6}$ en México y en el extranjero, la revista Futuro (uno de los órganos de la Universidad Obrera de México) se orientó a la lectura de trabajadores sindicalizados y comprometidos. Respecto de su diagramación y morfología, el Taller de Gráfica Popular tuvo incidencia en la fuerte presencia de imágenes ${ }^{7} \mathrm{y}$, en el plano textual, en la revista coexistieron sesiones estables como «El Perfil del Mes» (espacio de crítica satírica moralizante), «Cine» y «Libros» (crítica cinematográfica y literaria), ensayos sobre la situación socio-política, cultural,

${ }^{3}$ Expreso mi agradecimiento a los evaluadores por su lectura y comentarios

${ }^{4}$ Quiénes son los refugiados españoles. (julio de 1939). Futuro, (41), p. 22.

${ }^{5}$ Vicente Lombardo Toledano (1894-1968) fue un intelectual mexicano, abogado de profesión que lideró el plano sindical mexicano, latinoamericano y mundial. Fue unos de los dirigentes destacados de la Confederación Regional Obrera Mexicana (CROM) y Secretario General de las siguientes confederaciones obreras: Confederación General Obrera y Campesina de México (CGOCM) y Confederación de Trabajadores de México (CTM). Además, presidió la Confederación de Trabajadores de América Latina (CTAL) y en 1945 participó en París en el Congreso Obrero Mundial, donde fue elegido en forma como primer vicepresidente de la recién creada Federación Sindical Mundial (FSM). Sus esfuerzos siempre estuvieron encaminados a establecer un internacionalismo obrero. Como intelectual escribió casi un centenar de libros, estudios, ensayos y folletos sobre diversas materias. Fundó numerosas publicaciones periódicas, tales como Futuro o El Popular. Los aportes de Patricio Herrera (2014) y (2016) fueron imprescindibles para conocer el rol del Vicente Lombardo Toledano en tanto agente fundamental en materia del exilio republicano español y en el plano de conformación de unidad en el Movimiento Obrero.

${ }^{6}$ Tal como se enuncia en sus páginas: ¿Sabe usted que editamos y vendemos más de cuarenta mil números mensuales?; El Perfil del Mes. (enero de 1939). Futuro, (35), p. 26.

${ }^{7}$ El Taller de Gráfica Popular, colectivo artístico que puso primacía en el arte como medio para fomentar causas sociales revolucionarias, tuvo un rol protagónico en Futuro. Este taller estaba integrado por artistas como Siqueiros, O’Higgins, Kalho, Rivera y Beltrán, entre otros. 
económica y laboral de México y Latinoamérica. También la revista contó con producciones literarias de tinte antifascista. En este último caso, se destacó la poesía.

La vanguardia estética ${ }^{8}$ en Futuro también coincidió con la apertura a políticas de fuerte compromiso de solidaridad con los exiliados españoles tras el reciente fracaso de la República Española hacia 1939. ${ }^{9}$ Un ejemplo lo constituyó el propio fundador de la revista que, ad portas del fin de la Guerra, estableció junto con el presidente Lázaro Cárdenas políticas de recepción de intelectuales. ${ }^{10}$ Este período coincidió con un escenario de acogida promovido ya desde el gobierno de Cárdenas. De hecho, él mismo afirmaba que: «faltando en México, en general, investigadores debidamente preparados y siendo escasas entre nosotros las personalidades científicas de verdadero relieve, aparece indispensable hacer venir tal personal de otros países» (Mancilla Dosil y Ramos García, 2011, p. 290). ${ }^{11}$

Lo anterior revela que la revista, artefacto cultural de cierta autonomía, requiere ser estudiado de acuerdo a su lógica interna y no como evidencia de otra cosa. Al tratarse de una obra en constante movimiento,

\footnotetext{
${ }^{8}$ No hemos encontrado trabajos que se centren particularmente en el proceso de estetización de esta revista. Más bien, hemos notado que aparece mencionada entre otras publicaciones de la época como uno de los tantos ejemplos de vanguardia en México. Un ejemplo relevante es el aporte de José Rodríguez (2003) que dedica parte de su artículo al fotomontaje y otras expresiones plásticas en Futuro. Asimismo, Minguzzi (2007) y (2014) nos ha provisto de aportes de relevancia en materia de los intercambios estéticos que se realizaron entre las revistas en el contexto de Buenos Aires. Estos trabajos han sido de inspiración para la confección del artículo.

${ }^{9}$ Como afirma Plá Brugat (2007), en torno a 1939 se constituyó una brecha delimitadora entre el exilio y la idea de refugio en México, esto se debe a que antes de este año la categoría asociada a los recién llegados se emparentaba con una intención de acogida por medio del país receptor, mientras que luego de 1939, quienes arribaron ya se habían asentado en el espacio de recepción y eso los constituía como exiliados. Los aportes de Clara Lida proveen de un panorama claro de la recepción de los españoles del éxodo, particularmente en su trabajo «La España perdida que México Ganó» (2003).

${ }^{10}$ Como este caso, existen muchos otros que marcaron su paso por Futuro. Un ejemplo fue Silva Herzog, economista, intelectual y escritor que favoreció políticas de inclusión de espacios de investigación, creación y cultura para los exiliados españoles. Y, como muestra de esto, se sabe que León Felipe junto con el poeta Juan Larrea, habiendo trabajado ya desde España en la formación de la revista España Peregrina, contó con el apoyo de Herzog para la refundación de esta revista en México. Esta publicación se constituyó posteriormente, en 1942, en la reconocidísima Cuadernos Americanos. Sobre estos aspectos ver: Ojeda Revah (2013).

${ }^{11}$ Sobre estos aspectos ver también: Lida (1988).
} 
en la revista confluyen redes dialógicas. ${ }^{12}$ Este fenómeno se vuelve muy evidente en Futuro, no solo por tratarse de una publicación comprometida con el exilio sino por su intención de conformación de una red de compromiso y solidaridad a nivel internacional. De hecho, los cruces entre intelectuales transgredieron incluso las fronteras geográficas (distancia entre espacios de enunciación) y metafóricas (de concepciones estéticas y posiciones políticas). Esto se debe a que las ideas se vuelven también errantes y los temas fundantes de una época cobran protagonismo en un entramado de debates más amplio (Granados, 2012). En este marco, la revista evidencia la existencia de un campo intelectual, es decir, un sistema de líneas de fuerzas que se repelen, conviven, se rechazan o se atraen (Bourdieu, 2002). Todo esto sucede en un intercambio dialógico de enunciados. Estos últimos reflejan posiciones frente a las cuales se espera una reacción dialógica (Bajtín, 1979).

Futuro, entonces, fue un espacio de diálogos donde primaron ciertos interrogantes que esperaban una acción responsiva. En este trabajo hemos puesto foco en uno de los temas acuciantes de la revista, es decir, los enunciados referidos al exilio republicano español. Nuestro corpus, además de contar con una importante presencia de poesías, abre el espectro a otros géneros que también abordan la temática del éxodo entre 1939-1940. Nuestro objetivo es analizar estos diálogos y conocer su alcance hacia otros tipos de expresiones enunciativas y estéticas en el contexto de solidaridad frente al desembarco republicano en México. En definitiva, nos preguntamos cómo se constituye enunciativamente el exilio y de qué modo la poesía augura un espacio de solidaridad y refugio. Para tales fines, dispusimos el artículo en tres momentos: en primer lugar, notaremos que la revista actúa como un puerto de acogida. Futuro le da la palabra a escritores y artistas exiliados y, también, a intelectuales

\footnotetext{
${ }^{12}$ Nótese que la forma de autonomía que hemos atribuido a la revista no entra en conflicto con la idea de estudiarla usando la teoría dialógica de Bajtín. La propuesta por la autonomía de la revista es, ante todo, una propuesta por la elección de un énfasis. Tradicionalmente, los estudios en torno de las publicaciones periódicas situaron a la revista como un vehículo de ideas en Minguzzi, (2007) y (2014). También se la ha caracterizado como un soporte material desde donde se pueden visualizar escenarios sociales y culturales en Tarcus (2007). No olvidamos que el contexto cultural vuelve significativos los enunciados en la revista y que esta es una obra en movimiento que se reconoce en su interacción con diversos actores culturales (de ahí nuestro enfoque dialógico), sin embargo tampoco olvidamos que la revista ha sido más bien analizada realización de otro objeto (o bien un autor, o una escuela, o un movimiento o una tendencia ideológica) que como objeto de análisis de un campo autónomo. Nuestra perspectiva teórica toma inspiración en el trabajo de Louis (2014).
} 
comprometidos con la causa de la República. En segundo lugar, a partir de un ensayo presente en la revista, observaremos los espacios de encuentro («Verdades») y de rechazo («Calumnias») frente a la idea de la solidaridad con los refugiados. Finalmente, analizaremos un corpus de poesías publicadas en Futuro («Poemas de la Guerra») donde se perciben intercambios dialógicos que responden a una necesidad de solidaridad.

\section{La revista bace el presente del exiliado}

Suponemos tres cuestiones respecto Futuro. En primer lugar, que fue una revista cultural de izquierda que requiere ser tratada de manera autónoma. Esto no implica desatender las acucias del momento histórico pero sí brindarle independencia y autonomía respecto de la realidad que, en apariencia, refleja. En este punto, tal como Louis (2014) pensamos que las revistas son agentes activos de su gestación y, sin estos agentes, «resulta imposible aprehender el medio cultural y la identidad de una época» (p. 1). En segundo lugar, concordamos con la idea de Sarlo (1992) respecto a que cada revista posee una sintaxis particular que evidencia posiciones ideológicas y estéticas de quienes la integran y que esas posiciones se exhiben tras prueba y error, en las páginas de la revista. ${ }^{13}$ Estos artefactos autónomos intervienen en el presente (un presente que nos llega a nosotros, investigadores, en forma de pasado) y, en el caso de las revistas culturales de izquierda, tal como Futuro, lo hacen para provocar un cambio frente a una realidad que es adversa o injusta o que exige acción inmediata (tal es el caso del reciente arribo de españoles expulsados por la Guerra). En tercer lugar, entendemos que las revistas culturales requieren del diálogo entre intelectuales para su constitución. En este marco, Rocca (2004) señala que la revista debería ser sinónimo de «diálogo» puesto que recibe la mirada de sus contemporáneos que la interpelan, la comentan y, en definitiva, contribuyen en la respuesta de los interrogantes que la atraviesan.

Tomando como punto de partida los supuestos anteriores que Futuro inaugura un caso sin precedentes y un interrogante no analizado hasta el momento: ¿Cómo se posiciona, política y dialógicamente, la revista frente al éxodo? Siendo un artefacto autónomo, es decir, no solo

${ }^{13}$ Pluet Despatin (1992) considera la revista como laboratorio de ideas. Sus aportes han sido de suma inspiración para nuestro trabajo. 
documento de algo más ni valor ejemplar de un acontecimiento, ¿de qué modo la revista construye enunciativamente el éxodo?

Por empezar, Futuro intervino polifónicamente (permitiendo la coexistencia y yuxtaposición de voces) en un presente que exigía acción y compromiso. Ese presente, es decir, el contexto de producción -en términos de Louis- se situó en México en la primera mitad del siglo XX y la acción de la revista estuvo orientada hacia el repudio de los autoritarismos de Europa. La revista, además, hacía constantes referencias a la problemática del exilio y repudiaba la opresión en todas sus formas. También Futuro proclamaba la necesidad de aunar todas las fuerzas en la preparación y reacomodamiento luego de la Revolución Mexicana y la interpelación al obrero (particularmente se proclamaba un llamamiento a la unidad entre los trabajadores de América Latina) en tanto agente fundamental para general el cambio. También se reclamaba la atención de los trabajadores del arte cuya «tendencia (...) a la popularización es su mayor conquista revolucionaria». ${ }^{14}$

Respecto del caso particular del exilio republicano, Futuro promovía la solidaridad y el refugio y, no solo lo hacía desde la palabra sino desde la acción. En efecto, la revista dio voz a los intelectuales recientemente arribados al suelo latinoamericano. ${ }^{15}$ Esto se vuelve particularmente evidente en las publicaciones que van desde 1938 a 1940, momento en que se percibe una cuantiosa presencia de enunciados referidos al exilio. ${ }^{16}$ En este aspecto, Zuleta (1999) señala que el exilio literario republicano español se caracteriza por tres pérdidas: en primer lugar, la sensación de la pérdida de absolutamente todo; en segundo lugar, la pérdida del propio espacio y tiempo (ambos quedaron suspendidos del pasado en la tierra natal) y, finalmente, por la pérdida asociada a la

\footnotetext{
${ }^{14}$ Futuro, (julio de 1939), (41), p. 10.

${ }^{15}$ Futuro acoge la participación de españoles exiliados tales como Pedro Grafias, León Felipe, Josep Renau, etc. Por mencionar un caso, según Cabañas Bravo (2011) el artista Josep Renau se insertó laboralmente luego de su arribo a México gracias a la revista.

${ }^{16}$ Hacia 1939 la revista hacía constantes referencias al exilio. Por ejemplo, en abril se refirió a los niños exiliados en Francia y las precariedades del exilio. En mayo, cuenta las inclemencias de los refugiados en Francia recluidos en campos de concentración En agosto se destinaron varios artículos y ensayos a la cuestión de la Guerra Civil y sus consecuencias. En octubre se registró un número entero dedicado a la guerra donde se trata la problemática de España entre otros países asediados por regímenes opresores. Cfr: El Perfil del Mes. (abril de 1939). Futuro, (38); Cassou, J. (mayo de 1939). El destino de Francia. Futuro, (39); Agosto, Mes de Guerra. (agosto de 1939). Futuro, (42); Futuro, (octubre de 1939), (44).
} 
muerte, es decir, la pérdida definitiva de la posibilidad de morir como español. Estas pérdidas que experimenta el exiliado son percibidas por Futuro como una gran ganancia histórica y humana para México (Lida, 2003; Di Salvo y Herrera, 2016). En este contexto, la revista parece ser ese espacio de arribo, un puerto: desde ella zarpan columnistas a la lucha mancomunada en la Península, hacia ella llegan columnistas nuevos que requieren refugio:

Esta inmigración española que está por venir a México, es, precisamente por ser la última durante mucho tiempo, tanto más valiosa. Se dirá que México no debe precipitarse a recibirla, que espere algunos años que otros países la absorban y que después reciba 'el resto'. Si esto se hiciera, México recibiría inmigrantes de calidad más bien baja. Además, el problema de la despoblación de México es grave y exige que se aprovechen las buenas oportunidades ${ }^{17}$

Notemos que la apuesta por el refugio debatía contra un enunciado implícito, «lo que se dirá» respecto de la inmigración. La invitación a «hacer política» (Sarlo, 1992) que proponía la revista tenía el objetivo de construcción de un porvenir (Di Salvo y Herrera, 2016) adelantarse a lo que dirían. Futuro insistía en la conformación de una versión mejorada del presente $\mathrm{o}$, al menos, reaccionaba dialógicamente frente al enunciado del rechazo. En palabras de los editores de la revista «FUTURO se propone servir, en la medida de las posibilidades con que cuenta una publicación de su género, a la sociedad de mañana». ${ }^{18}$

La sociedad de mañana se construía con solidaridad. Esta solidaridad era una política estructuradora de la revista que se manifestaba ya desde las editoriales de varios números y también en las elecciones estéticas. De ejemplo valen dos imágenes: el trabajo del dibujante Cardenio ${ }^{19}$ quien publica «El pueblo mexicano recibe a sus hermanos españo-

${ }^{17}$ Futuro, (junio de 1939), (40), pp. 10-13.

${ }^{18}$ Editorial. (diciembre de 1933). Futuro, (1), p. 4.

${ }^{19}$ José González -Seudónimo: Cardenio- (1889-1943) Fue un caricaturista nacido en España que vivió gran parte de su infancia y juventud en Chile. En Santiago participó en El Diario Ilustrado en 1916 y, en España, publicó caricaturas y viñetas de humor gráfico en la prensa madrileña durante alrededor de los años treinta del siglo XX en el diario La Voz y semanarios como Buen Humor. En 1936 apareció un libro antológico con una selección de caricaturas suyas titulado Todo el mundo sabe que esto son diez dedos prologado por de Ramón Gómez de la Serna. Notamos que en torno a los años de la Guerra Civil Española, Cardenio ofrece varios trabajos a la revista Futuro. El dibujante murió en México en 1943. 
les» (Imagen 1$)^{20} \mathrm{y}$, con una página de diferencia, la caricatura de Luis Audirac (Imagen 2) ${ }^{21}$ que exhibía el «imperio» de Franco quien desde abajo observaba al emperador Mussolini. Estas dos imágenes en el mismo contexto de publicación permiten notar el posicionamiento de la revista ante el exilio y la importancia de recibir a los «hombres que empuñaron las armas en favor del gobierno legítimo de España y que lucharon por la democracia». ${ }^{22}$ Asimismo, nos permite ver que el intercambio estético es fundamental para sostener las ideas que sostiene cada vehículo cultural. ${ }^{23}$

\section{Imagen 1}

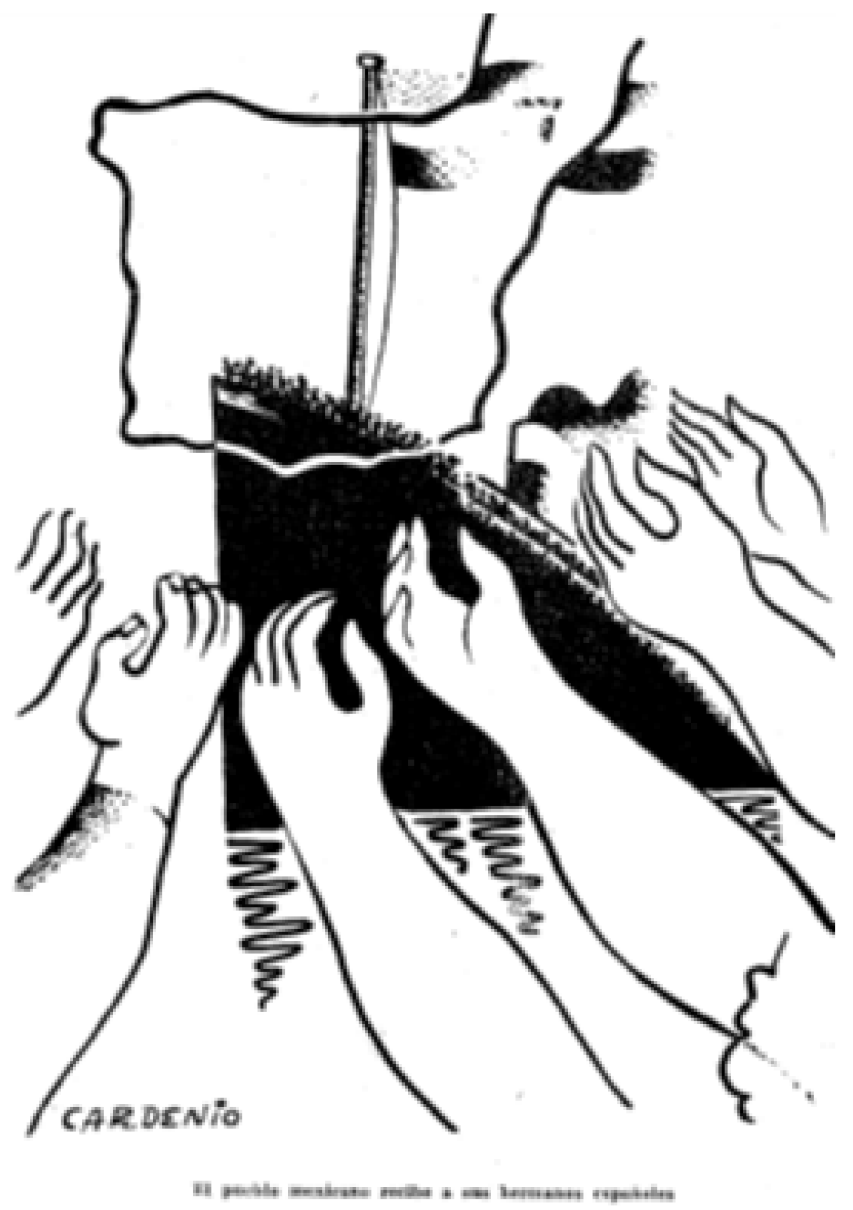

${ }^{20}$ Cardenio. (junio de 1939). El pueblo mexicano recibe a sus hermanos españoles. Futuro, (40), p. 11.

${ }^{21}$ Audirac, L. (junio de 1939). Este es el «imperio» de Franco. Futuro, (40), p. 13.

${ }^{22}$ Loyo, G. (junio de 1939). La inmigración española. Futuro, (40), pp. 10-13.

${ }^{23}$ Se sugiere la lectura de Minguzzi (2014). 


\section{Imagen 2}

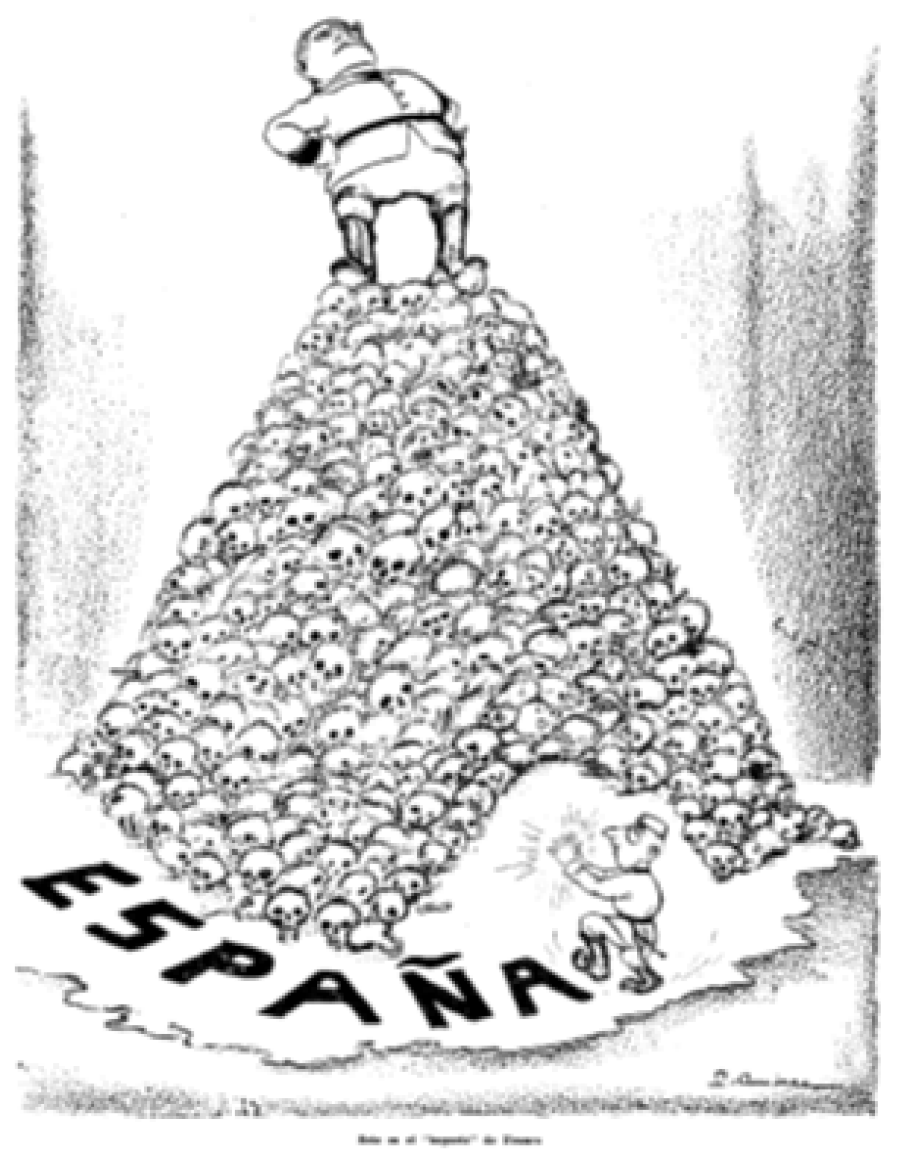

Como se prevé, el exilio constituyó un dilema para el entramado de relaciones textuales, políticas, gráficas y editoriales de Futuro. En este aspecto, la revista conformó un entramado dialógico de enunciados multiacentuales en los que se perciben el cruce de una o más voces. En este cruce de voces se entablaron relaciones dialógicas y son éstas relaciones las que permiten vislumbrar posiciones de diferentes sujetos a través de la palabra ya vuelta enunciado (Bajtin, 1979). Podemos notar un ejemplo en la voz de Octavio Paz, quien hacia enero de 1939, escribió en la revista un ensayo donde expuso las diversas críticas y prejuicios que había recibido «lo español» desde Latinoamérica. En este trabajo, Paz ofrece una respuesta ante el interrogante de la tragedia española:

lo trágico del dilema obliga a la acción, heroica y solidaria. La defensa de España es la defensa de América. iLuchemos en el Frente Americano, por la victoria del Pueblo Español! (...) «No sabían que 
al combatir a la España republicana, a la del Frente Popular, combatían también a la América» $(\ldots)^{24}$

$\mathrm{Al}$ interior del ensayo, en el mismo contexto de publicación, aparecía un comentario enmarcado de Jacinto Benavente ${ }^{25}$ titulado «Treinta meses después». Las palabras del escritor entran en diálogo con el escrito de Paz:

A los dos años de lucha, mi fe en el triunfo del pueblo es cada vez mayor (...) Digo el triunfo. Triunfar no es siempre lo mismo que vencer; pero es ley de la Historia que no ha fallado nunca, avanzar siempre, siempre. (...) Digamos, pues, muy alto: iViva la verdadera España, la que quiere vivir!26

Este ejemplo de cruce de enunciados además de posicionar políticamente a los autores, permite observar la riqueza polifónica de esta revista. Las fronteras de un enunciado, tal como señala Bajtin, están delimitadas solamente por el cambio de los sujetos discursivos. Esto implica que un interrogante admita respuestas plurales, lo cual lleva a la imposibilidad de clausura de un debate o polémica. En este caso, el interrogante gira en torno del fracaso de la República y sus consecuencias directas sobre una Latinoamérica que Futuro construyó enunciativamente como un espacio de solidaridad. Esta posición asumida por Futuro, desde luego, combatía contra otra palabra, la palabra ajena que pugnaba por el rechazo hacia la República.

\section{«Quiénes son los refugiados españoles: Verdades y calumnias»}

«Esos puños cerrados están prestos a descargarse» ${ }^{27}$ Excelsior, 15 de junio

Bajo este título (las palabras son citadas textualmente de un ensayo del no 41 de Futuro, julio de 1939) apareció en la revista una serie de

\footnotetext{
${ }^{24}$ Paz, O. (enero de 1939). Americanidad de España. Futuro (35), pp. 18-19.

${ }^{25}$ Jacinto Benavente (Madrid, 12 de agosto de 1866-Galapagar, 14 de julio de 1954) fue un dramaturgo, director, guionista y escritor de poesía. Se consagró premio Nobel de Literatura en 1922.

${ }^{26}$ Benavente, J. (enero de 1939). Treinta años después. Futuro, (35), pp.18-19.

${ }^{27}$ Quiénes son los refugiados españoles. (julio de 1939). Futuro, (41), p. 22.
} 
fragmentos de enunciados extraídos de diversas publicaciones. Los editores construyeron una especie de collage tomando las palabras de «la prensa conservadora [que] continuará desarrollando con más saña que nunca, su obra de desorientación y calumnia». La intención es hacer frente a la ofensiva reaccionaria ${ }^{28}$ que se ocupaba de tergiversar la información con «Calumnias»:

AQUÍ estamos perfectamente conformes con recibir al Romancero en pleno - aunque haya quien opine que Mio Cid no fue más que un Pancho Villa de los tiempos en que se usaban ni la pistola ni el texano- - y 110 tendríamos inconveniente en darle una tarjeta, forma número 14, ylionoris causa a nuestro buen señor Don Quijote (...). (Excelsior, 3 de junio $)^{29}$

Futuro tomaba la palabra ajena para desafiarla. Podemos observar que en Excelsior se señala conformidad en «recibir al Romancero en pleno». La voz de esta publicación nos remite (a nosotros y al posible lector de 1939) a la obra del poeta fusilado apenas tres años antes de la publicación de estas palabras. El Romancero Gitano de Lorca lleva en sí mismo la esencia del canto popular andaluz y la carga terrible de la muerte del poeta. Ya se habría lamentado la muerte de Federico García en esta revista y los lamentos continuaban incluso hasta 1939 cuando, con motivo de la muerte de Antonio Machado, Futuro señalaba que «no es de extrañarse $[\ldots]$ que mañana algún fascista perverso pretenda decir que Machado fué falangista y que lo mataron los «rojos», tal como lo han pretendido hacer manchando la memoria de García Lorca». ${ }^{30}$ Con el filo de ese enunciado, Excelsior atentaba contra la literatura popular acaso como referencia metonímica a los refugiados que llegaban a México. En efecto, este ataque enunciativo se realizaba por medio de una apropiación de voces ajenas para mostrar distancia y rechazo (honoris causa por «ylionoris causa»). Sin duda, este fue el comienzo de un debate polifónico donde se visualizaban las posiciones frente al interrogante del exilio: Futuro, como publicación afín a la idea del refugio y, desde el bando de los periódicos retractores se encuentran Hoy, Excelsior y La Prensa. Desde el segundo bando se señala que «los republicanos íberos que en su

\footnotetext{
${ }^{28}$ Esto ya se anticipa en números anteriores, como por ejemplo: Lector. (enero de 1939). Futuro, (35), p. 33.

${ }^{29}$ Quiénes son los refugiados españoles. (julio de 1939). Futuro, (41), p. 21.

${ }^{30}$ El Perfil del Mes. (marzo de 1939). Futuro, (37), pp. 28-30.
} 
mayoría han llegado carentes de medios de vida, ya empiezan a constituir una difícil situación y han creado un serio problema que tiende a agravarse; cada día más... (La Prensa, 3 de junio)». También se sostiene que los exiliados son «puños cerrados [que] están prestos a descargarse», enunciado que actúa como una sinécdoque, donde se toma «lo puños cerrados» como de la totalidad de republicanos que llegan a México. Además, se agrega que estos «puños cerrados» están «[...] impulsados por la dinámica roja acumulada en tierras extrañas, contra pechos mexicanos que albergan los mismos sentimientos sectarios que el licenciado Lombardo Toledano (Excelsior, 15 de junio)».

Notemos la apelación directa al fundador de la revista. La elección de la cita, por parte de los editores de Futuro, y la decisión de incluirla en la publicación da muestra de la necesidad de evitar la clausura de este debate. Finalmente «el peligro mayor», según la prensa reaccionaria, se vinculaba con la posibilidad de que se integrasen al medio de lucha de la Confederación de Trabajadores Mexicanos (CTM):

[...] Pero resulta que los refugiados no vienen a sumarse al país, sino a engrosar las filas de la CTM. No traen la paz, sino la guerra; no son huéspedes de México, sino de Lombardo Toledano. En semejantes circunstancias, a nadie debe extrañar que si la secta está de plácemes, la nación se halle profundamente resentida [...]. (Hoy, 24 de junio)

Los últimos enunciados, referidos a Vicente Lombardo Toledano, permiten situarlo en una red polifónica multiacentual donde los detractores lo construyeron enunciativamente como agente relevante en materia del exilio. ${ }^{31}$ Posiblemente a eso se refería François Dosse (2007) cuando señalaba que la noción de intelectual es polisémica puesto que reviste concepciones diferentes según una multiplicidad de los regímenes de la historicidad (p.20). Lombardo Toledano tuvo un rol fundante en la acogida de republicanos, responde a las «Calumnias» anteriores y lo hace con «Verdades». En este apartado, el fundador de Futuro, reconocía «algunos de los distinguidos intelectuales que han arribado a México, hu-

\footnotetext{
${ }^{31}$ Herrera (2014) realiza en este marco un aporte de suma relevancia para conocer la participación mancomunada de Vicente Lombardo Toledano con el presidente Lázaro Cárdenas en la acogida de los españoles del éxodo y su colaboración activa con la conformación de una conciencia antifascista en México y Latinoamérica.

${ }^{32}$ Quiénes son los refugiados españoles. (julio de 1939). Futuro, (41), p. 22.
} 
yendo de la barbarie fascista que ha dominado su patria» ${ }^{32}$. Entre ellos se encontraba una lista vasta donde aparecían trabajadores, fundadores de revistas, editores, educadores, médicos, compositores, escritores y poetas. Notemos algunos ejemplos:

Josep Renau: ${ }^{33}$ Cartelista y pintor; Director General de Bellas Artes; Profesor de la Escuela de Bellas Artes de Valencia; Director y fundador de la Revista Nueva Cultura Emilio Prados: Poeta de la nueva generación del comité editor de la revista Hora de España, editada en plena guerra. (...)

León Felipe: Famoso poeta residente en América, que al estallar la güera marchó a España para estar al lado del pueblo en la defensa de su Patria (...)

Pedro Garfias: Poeta. Leonardo Ontañón: Novelista (...).

Lorenzo Varela: Escritor y poeta. (...)

Juan Gil Albert: Poeta, redactor de Hora de España

La réplica de Vicente Lombardo Toledano evidenciaba un entramado de relaciones dialógicas que posicionaban políticamente la revista. Las voces ajenas (las «calumnias» sobre el exilio), introducidas en un discurso particular de la revista, adquirían una nueva comprensión de las problemáticas del exilio. Futuro tomaba la voz del «enemigo» (la prensa reaccionaria) para reafirmar sus propias ideas (las «verdades» sobre el exilio) vueltas enunciados. Esta nueva valoración que le confiere Futuro a la palabra ajena, convierte a esta última en una palabra bivocal que «no penetra personalmente en el discurso, sino que apenas se refleja en el» (Bajtín, 1979, pp. 272-274). Y son esos reflejos los que resultan interesantes para nuestro análisis. En este caso particular, la inclusión de enunciados tomados de Hoy, Excelsior y La Reacción embestían contra la posición dialógica e ideológica de Futuro. El mismo efecto se sostenía con el Universal, Novedades y Ultimas Noticias, llamadas de manera irónica «Necedades» $\mathrm{y}$ «Ultimas Mentiras». ${ }^{34}$ Estas publicaciones se constituyeron

\footnotetext{
${ }^{33}$ Según Cabañas Bravo (2011) Josep Renau «pudo reanudar el trabajo gráfico desde su llegada en 1939, gracias al contrato que le hizo el impresor de origen español Santiago Galas, que tenía una imprenta dedicada a carteles, calendarios e impresos publicitarios. Además, a principios del 1940, a través de sus contactos con el líder sindical Vicente Lombardo Toledano, secretario de Confederación de Trabajadores de México, inició su colaboración con la editorial y revista Futuro, órgano de expresión de la Universidad Obrera de México» (p.25).

${ }^{34}$ Notemos dos de los múltiples ejemplos en los siguientes ensayos satíricos de la sesión
} 
como medios opositores a Futuro y esa oposición se manifestaba a través de los enunciados, que permiten notar las disputas ideológicas dentro del «clientelismo posrevolucionario».

\section{Solidaridad poética: cantar o morir}

«Perdóname el lenguaje
difícil de mis versos.
Quisiera hablar contigo
la voz de tu silencio»
Pedro Garfias, «Pueblo»

En su libro, Caudet (1993) señala que al finalizar la Guerra Civil emergieron en Europa movimientos de vanguardia que rompieron con los cánones estéticos entonces vigentes (proliferaron producciones ultraístas, futuristas, dadaístas y creacionistas). Sin embargo, y dado el acuciante conflicto que atravesaba España, se volvió presente el arte comprometido e, incluso, el arte de propaganda como medio de defensa del pueblo republicano. La Guerra, señala Caudet (1993) «supuso la concreción de un nuevo arte, de una escritura coherente con la revolución» (p. 239). Este proceso estético-literario fue acompañado desde las páginas de Futuro: frente a un mundo que se había roto y debía ser reconstruido, la palabra era un espacio para hacer, construir la solidaridad poética. En efecto, en julio de 1938, la revista dedicó cuatro páginas para homenajear a los poetas que defendieron al pueblo español. Los versos fueron anticipados, en el índice, como «Poemas de la Guerra»: ${ }^{35}$

Es conocida por todo mundo la actitud de los intelectuales españoles en el conflicto creado en su patria por el fascismo internacional. Singularmente los poetas se han distinguido en el fervor democrático, capitaneados, por decirlo así, por los dos maestros de la poesía contemporánea: Antonio Machado y Juan Ramón Jiménez. Coincidiendo con los poetas españoles, casi todos los poetas del mundo han dado su adhesión a la causa de la democracia española. Los poetas hispanoamericanos - Neruda, César Vallejo (...), etc. luchan tam-

estable «El Perfil del Mes», espacio donde se ofrecía una crítica al accionar reaccionario de la prensa, intelectuales, artistas o políticos: El Perfil del Mes. (julio de 1939). Futuro, (41), pp. 19-21; El Perfil del Mes. (junio de 1939). Futuro, (40), pp. 17-19.

${ }^{35}$ Futuro, (julio de 1938), (29), p. 1. 
bién por sus hermanos de habla y de ideales; en México los nombres de González Martínez, Alfonso Reyes (...) y los de toda la juventud literaria, iluminan la actitud de los intelectuales honrados de nuestro país, pese al obscuro y cobarde silencio de otros. FUTURO publica ahora algunos de los poemas que la actual lucha ha inspirado. Honra así al pueblo de España en lo mejor de su patrimonio artístico: la palabra creadora ${ }^{36}$

Los poetas hispanoamericanos y los mexicanos luchaban con la palabra a la par de «sus hermanos de habla e ideales». Esta muestra de solidaridad constituyó un eje fundante en esta publicación que se había forjado desde años anteriores. En efecto, Juan Ramón Jiménez anticipaba ya en 1936 la necesidad de que «ayudemos todos para que nuestra España vea del todo en medio de su tormenta, para conseguir de nuestra España esta doble gloria, este doble ejemplo que le traerá para siempre el respeto universal» ${ }^{37} \mathrm{Tal}$ como puede percibirse, las redes dialógicas emprendieron un entramado que se tejía número a número y se fortalecía para combatir una realidad que, entre 1936 y 1939, se volvía cada vez más adversa.

Lorenzo Varela, Antonio Machado, Rafael Alberti, Pedro Garfias, Max Aub, Pablo Neruda, Miguel Hernández, Enrique Diez-Canedo y Juan Gil-Albert fueron los poetas elegidos por Futuro en 1938 para cantar frente a la muerte que asediaba la Península. Notemos que algunos de estos nombres eran «defendidos» por Vicente Lombardo Toledano en 1939, tal como señalamos en el apartado anterior. Entonces, frente a la sensación de vacío (o "pérdida», en términos de Zuleta) que suscitaba la censura de expresión del franquismo y el consecuente exilio de numerosos intelectuales, la revista abría diálogos. La poetización, en este aspecto, no era solo un modo posible de llenar este vacío, sino el más adecuado. ${ }^{38}$ En efecto, Burello (2011) señala que «el destierro no solo impide la poetización, sino que puede resultar un motivo perfecto para promoverla» (p.281).

\footnotetext{
${ }^{36}$ Futuro, (julio de 1938), (29), p. 34.

${ }^{37}$ Hablan los intelectuales de todo el mundo: Juan Ramón Jiménez. (octubre de 1936). Futuro, (8), p. 12.

${ }^{38} \mathrm{Si}$ bien Marcelo Burello se refiere al exilio en la obra de Joyce notamos que hay puntos en común con las producciones poéticas citadas en nuestro trabajo. Uno de estos puntos en común es la idea de crear una «poética de la ausencia» y el concepto de epifanía que emplea el autor, en tanto acceso a una verdad revelada.
} 
Los poemas anteriores estaban insertos como un «Homenaje a los poetas que defienden su pueblo» donde se abordaban tres modos de solidaridad: la primera, era por medio de la acusación a Franco, la segunda tenía que ver con el empoderamiento del trabajador como agente de lucha y la tercera estaba asociada a un sentimiento de empatía con el Pueblo. En el primero de los casos destaca el poema «El General Franco en los Infiernos» de Neruda. ${ }^{39}$ En estos versos se construía un deseo de muerte al General y la sinécdoque se extiendía al accionar opresivo de la falange. La «mal nacida palidez de la sombra» de Franco era causante y culpable de la muerte y la expulsión. El poema exigía, entonces, justicia en la soledad y la maldición:

Como el agudo espanto o el dolor se consumen, ni espanto ni dolor te aguardan. Solo y maldito seas, solo y despierto seas entre todos los muertos, y que la sangre caiga en ti como la lluvia, y que un agonizante río de ojos cortados te resbale y recorra mirándote sin término ${ }^{40}$

En esta misma línea polifónica, apareció el poema de Max Aub ${ }^{41}$ titulado «A un Fascista» que contribuía en la destrucción de las «máquinas traidoras» de Franco y separaba los dos bandos de lucha en un «allí» y un «aquí»:

Allí con tus máquinas traidoras, aquí nosotros con desnudas manos a ti la muerte todo te lo veda, cada muerte me da nuevos hermanos

\footnotetext{
${ }^{39} \mathrm{Al}$ finalizar la Guerra Civil, el poeta (nombrado Cónsul de especial para la inmigración republicana española con sede en Francia), se sensibilizó por las miserables condiciones en las que vivían los refugiados republicanos en el país galo. Por tal motivo, lleva a cabo la empresa de trasladar 2000 víctimas a bordo del Winnipeg. El 3 de septiembre de 1939, los republicanos españoles arribaron al puerto de Valparaíso.

${ }^{40}$ Futuro, (julio de 1938), (29), p. 38.

${ }^{41}$ Max Aub (Paris, 1903- Ciudad de México, 1972), presenció la Guerra en Valencia y, tras tres años de internación en los campos de concentración, Aub -socialista de origen judíollegó a México en 1942. Su participación poética en Futuro es anterior a su exilio y se suma a otros trabajos publicados simultáneamente en México y España.
} 
Los poemas publicados en estas cuatro páginas de la revista conferían un nuevo sentido a la solidaridad frente a los agentes de expulsión y muerte en la península. Se combatía con la palabra desde diferentes ángulos, mientras Aub y Neruda reaccionaban ante el accionar del fascismo, Lorenzo Varela le cantaba a las muertes «luminosas». El poeta se refería al «joven héroe» que luchó y murió en batalla. ${ }^{42}$

Muerto, tu vida enamorada,

A tu pasión y gloria no da fin:

Que presa la lleva, de tu asombro,

Tu enamorado, tu luminoso morir

En el segundo de los casos anunciados con anterioridad, destacaron Rafael Alberti y Miguel Hernández quienes colaboraban en la construcción de solidaridad poética por medio del empoderamiento del trabajador. ${ }^{43}$ Estos, como otros poetas de la época, veían el compromiso y el trabajo como un escenario particular donde la poesía comenzaba a «obedecer a una necesidad, a servir, a ser útil» (Caudet, 1993:250). Esto se vislumbra particularmente en «El sudor» de Hernández y, el «Los Campesinos» de Alberti. Este último da una pincelada de la lucha del obrero que, tal como una semilla, se siembra en las trincheras:

[...] van los hombres del campo, como inmensas simientes

A sembrarse en los hondos surcos de las trincheras.

Muchos no saben nada. Mas con la certidumbre

del que corre al asalto de una estrella ofrecida,

de sol a sol trabajan en la nueva costumbre

de matar a la muerte, para ganar la vida ${ }^{44}$

\footnotetext{
${ }^{42}$ Lorenzo Varela, poeta español criado en Latinoamérica, formó parte del Partido Comunista y participó en el frente de batalla al iniciar la Guerra, se enroló en el frente de batalla durante la Guerra Civil y padeció el exilio en Buenos Aires, en México y en Montevideo. Participó en publicaciones republicanas tales como El Mono Azul y Hora de España. No hemos notado trabajos centrados en la participación del poeta en Futuro pero sabemos que trabó amistad con Octavio Paz con quien participó en la revista Taller: poesía y crítica, escenario por el cual pasaron otros poetas que también colaboraban con Futuro (López García y Aneiros Díaz, 2005).

${ }^{43}$ Rafael Alberti, integrante del Partido Comunista, participó activamente en la causa republicana. Al finalizar la Guerra Civil, el poeta se exilia en Paris. Posteriormente, y dada la amenaza alemana, en 1940 el poeta vuelve al exilio rumbo a Buenos Aires.
}

${ }^{44}$ Futuro, (julio de 1938), (29), p. 34. 
En el tercer caso, se perciben versos de empatía y solidaridad que buscaban un hermanamiento entre españoles y latinoamericanos. En este marco, se promovía la idea de «Ser como tu» que Pedro Garfias ${ }^{45}$ anticipaba en su poema «Pueblo»:

Ser como tu y no mas, como tus hijos, iPueblo!, ni mejor ni peor ni ultimo ni primero: una onda en las ondas de tu torrente negro

\section{A modo de conclusión}

Lejos de ofrecer un panorama acabado del entramado de diálogos que atravesaron Futuro, hemos notado algunas constantes que nos permiten ver cómo se constituyó enunciativamente el exilio republicano español y de qué modo la poesía auguró un espacio de solidaridad en la revista. Hemos notado que esta última fue un artefacto cultural autónomo y que, por ende, requiere ser tratada con relativa independencia del presente en el cual intervino. En este contexto, la revista construyó un espacio de lucha, solidaridad y necesidad de involucrarse políticamente frente a un fascismo que oprimía a Europa y que expulsaba a gran número de intelectuales al éxodo. La revista Futuro, con el rol protagónico de Vicente Lombardo Toledano (denunciado ya por la prensa opositora), oficiaba de puerto de arribo, tal es así que desde Excelsior -tal como aparece en acápite de nuestro artículo- se enunciaba que los exiliados no eran huéspedes de México sino del fundador de la revista. Este entramado multiacentual permite notar de qué modo las voces debatían en torno a la cuestión del exilio. En esta trinchera, los intercambios eran polifónicos y yuxtapuestos, se cruzaban voces pero siempre se identificaba la

\footnotetext{
${ }^{45}$ Pedro Garfias (1901-1967), fue un poeta del exilio que participó en la revista vanguardista y estridente Ultra y fundó la revista Horizonte en 1922, donde publicaron García Lorca, Machado y Alberti. Escribió poesías y las recitó en las líneas del frente de guerra y en las estaciones de radio. En 1939 arriba a México, a bordo del Sinaia, junto con otros 1800 refugiados, en agradecimiento al pueblo y al gobierno de Lázaro Cárdenas escribió, para representar a los tripulantes en su poema «Entre España y México» Mendívil Macías Veladez,(2011). En la misma línea aparecen estos versos en las páginas de Futuro.
} 
postura solidaria de Futuro («Verdades») frente a las tergiversaciones de la prensa enemiga («Calumnias»). La poesía («Poemas de la Guerra») es un claro ejemplo de esta posición asumida por la revista. Los versos (tejidos en una trama multiacentual) conforman lo que denominamos frente poético solidario que sitúa la palabra como medio fundamental de acción solidaria ante una realidad adversa.

\section{Referencias}

Bajtín, M. (1979). Problemas en la Poética de Dostoievski. México: Fondo de Cultura Económica.

Bourdieu, P. (2002). Campo de poder, campo intelectual. Buenos Aires: Montressor Jungla Simbólica.

Burello, M. (2011). James Joyce: el exilio como poética. En M. Burello, F. Ludueña Romandini y E. Taub (Eds.). Politicas del Exilio: origenes y vigencia. Buenos Aires: Eduntref.

Cabañas Bravo, M. (2011). Grandes Genios del Arte de la Comunitat Valenciana: Josep Renau. Valencia: Aneto Publicaciones.

Caudet, F. (1993). Las cenizas del Fénix: La Cultura española de los años 30. Madrid: Ediciones de la Torre.

Di Salvo, L. y Herrera, P. (2016). ¿Poéticas del exilio? El caso de Timón y Futuro (1939). Latinoamérica, Revista de estudios latinoamericanos (62), 13-34.

Dosse, F. (2007). La marcha de las ideas. Historia de los intelectuales, historia intelectual. Valencia: Universidad de Valencia.

Granados, A. (2012). Las revistas en la historia intelectual de América Latina: redes, intelectuales, politica y sociedad. México: Juan Pablos Editor.

Herrerra, P. (2014). La cuestión franquista y la posición obrera latinoamericana: las acciones de Vicente Lombardo Toledano. En M. Serra Puche, J. Mejía Flores y C. Sola Ayape (Eds.). 1945, Entre la euforia y la esperanza: el México posrevolucionario y el exilio republicano español (pp. 213-230). México: Fondo de Cultura Económica.

Herrera, P. (2016). Vicente Lombardo Toledano y su cruzada obrera continental: entre colaboraciones y conflictos (1927-1938). Revista Izquierdas (26), 41-66. 
Lida, C. (1988). La Casa de España en México. México: Centro de Estudios Históricos del Colegio de México.

Lida, C. (2003). La España perdida que México ganó. Letras Libres (56), 12-15.

López García, X. y Aneiros Díaz, R. (2005). Lorenzo Varela en Revistas Culturais de México e Bos Aires. Santiago de Compostela: Consello da Cultura Galega.

Louis, A. (2014). Las revistas literarias como objeto de estudio. Revistas Culturales 2.0. Recuperado de: https://www.revistas-culturales.de/ es/buchseite/annick-louis-las-revistas-literarias-como-objeto-deestudio

Mancilla Dosil, F. y Ramos García, J. (2011). Tejer el Destierro. Las redes científicas del exilio español en México. En M. Serra Puche, J. Mejía Flores y C. Sola Ayape (Eds.). De la posrevolución mexicana al exilio republicano español (pp. 283-307). México: Fondo de Cultura Económica.

Mendivil Macías Veladez, J. (2011). Pedro Garfias. Un poeta emblemático del exilio español. Cuarto Congreso Internacional CELEHIS de Literatura, Mar del Plata, Argentina.

Minguzzi, A. (2007). La revista Martín Fierro de Alberto Ghiraldo (19041905): pasiones y controversias de una publicación libertaria. Martín Fierro. Revista Popular Ilustrada de Critica y Arte (pp. 1966). Buenos Aires: Academia Argentina de Letras / Cedinci.

Minguzzi, A. (Ed.). (2014). La revista Ideas y Figuras de Buenos Aires a Madrid (1909-1919): Estudios e indices. La Plata: UNLP. FaHCE. IdIHCS (UNLP-CONICET).

Ojeda Revah, M. (2013), Jesús Silva Herzog y los intelectuales del exilio republicano español. En Santana, A. (Coord.). Setenta años de Cuadernos Americanos (pp. 17-30). México: CIALC, UNAM.

Plá Brugat, D. (2007), Pan, trabajo y hogar. El exilio republicano español en América Latina. México: Secretaría de Gobernación, Instituto Nacional de Antropología e Historia, DG E Editores.

Pluet-Destapin, J. (1992). Une contribution à l'histoire des intellectuels: les revues. En N. Racine y M. Trebitsch (Dir.). Sociabilités intellectuelles: lieux, milieux, réseaux (Les Cabiers de L'IHTP 20) (pp. 125136). París: CNRS. 
Rocca, P. (2004). Por qué, para qué una revista (Sobre su naturaleza y su función en el campo cultural latinoamericano). Hispamérica: revista de literatura (99), 3-19.

Rodríguez, J. (2003). Fotomontaje en México: razones sociopolíticas. Antropología Boletín Oficial del INAH (71), 3-12.

Sarlo, B. (1992). Intelectuales y revistas: razones de una práctica. America-Cahiers du CriCCal (9), 9-16.

Zuleta, E. (1999). Españoles en la Argentina. El exilio literario de 1936. Buenos Aires: Atril. 